\title{
Lutowanie laserowe w przemyśle motoryzacyjnym metodą Trifocal na przykładzie tylnej klapy Volkswagena Caddy
}

\author{
Laser brazing Trifocal in automotive industry \\ on the example of rear door of Volkswagen Caddy
}

\section{Streszczenie}

W przemyśle motoryzacyjnym coraz popularniejsze i coraz powszechniej stosowane są technologie laserowego łączenia materiałów, a zwłaszcza lutowanie wysokotemperaturowe z użyciem promieni lasera jako źródła ciepła. Niemal każdy producent samochodów wykorzystuje tę technologię, najczęściej do łączenia dachu pojazdu ze ścianami bocznymi oraz przy łączeniu blach karoseryjnych tylnych klap i pokryw bagażników.

Słowa kluczowe: lutowanie laserowe; laser; technologia lutowania; złącze lutowane

\section{Abstract}

The laser technology of material joining, especially hightemperature brazing technology with the use of laser beams as the heat source is gaining more and more popularity and is finding increasing use in the automotive industry. Almost every renowned carmaker uses such a technology, mostly to join the car roof with side walls and to join the car body sheets of the tailgate and boot covers. The newest method used in the automotive industry is Trifocal brazing.

Keywords: laser brazing; laser; brazing technology; brazed joint

\section{Wstęp}

Bezpośrednią przyczyną wzrostu zainteresowania technologiami laserowymi jest coraz łatwiejszy dostęp do tych technologii oraz malejące koszty wdrożenia ich do produkcji, zwłaszcza wielkoseryjnej. Znaczącą rolę odgrywa tu również miniaturyzacja urządzeń, która wkroczyła w obszar konstrukcji źródeł laserowych i chłodnic. Jeszcze kilkanaście lat temu źródła laserowe były wielkimi konstrukcjami o kilkumetrowej długości i wadze kilku ton (np. Trumpf HL 4006D [3]), a obecnie są to niewielkie urządzenia, porównywalne wymiarami do średniej wielkości lodówki (np. IPG YLS-5000-BR). Porównanie gabarytów źródeł laserowych starej generacji z najnowszymi urządzeniami pokazano na rysunku 1. Dodatkowo wyposaża się te urządzenia w proste podwozia kołowe, które umożliwiają bezproblemowe przemieszczanie sprzętu na hali produkcyjnej. Wszystkie te cechy powodują, że można zastosować te urządzenia w miejscach o ograniczonej powierzchni.

\section{Źródło laserowe}

Technologię lutowania wysokotemperaturowego elementów tylnej klapy w samochodzie Volkswagen Cad-

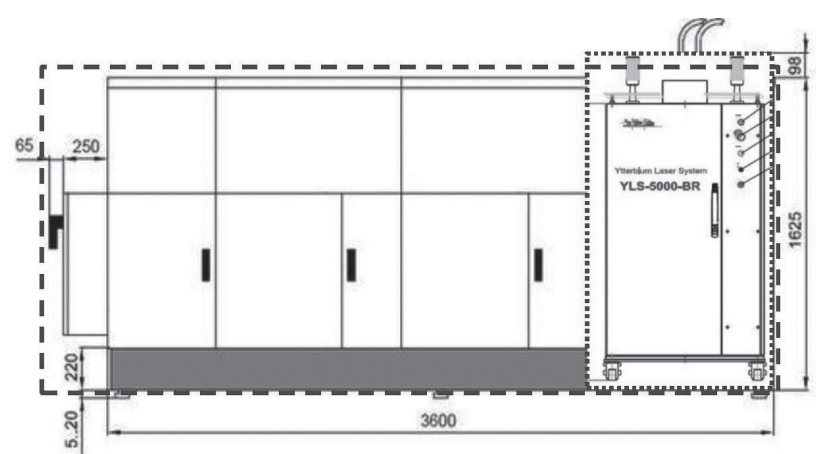

Rys. 1. Porównanie gabarytów lasera prętowego Trumpf HL4006D (2003 r, kontur - - -) z laserem YLS-5000-BR firmy IPG (2015 r.) - kontur ......

Fig. 1. Overall dimensions of the rod laser Trumpf HL4006D (2003) - - - and the laser IBG YLS-5000-BR (2015) ......

dy przedstawiono na przykładzie źródła laserowego YLS-5000-BR rosyjskiej firmy IPG o mocy $5 \mathrm{~kW}$ (rys. 2). Jest to nowoczesny laser włóknowy, gdzie promieniowanie laserowe wytwarzane jest w specjalnym światłowodzie, który jest pompowany przy pomocy odpowiednio dobranych pakietów diod laserowych. Konstrukcja tego źródła sprawia, że jego sprawność wynosi $42 \%$, co jest obecnie wynikiem doskonałym, choć trwają już

Mgr inż. Edward Majeran - VW Poznań Sp. z o.o.

Autor korespondencyjny/Corresponding author: edward.majeran@vw-poznan.pl 
prace nad źródłami o sprawności powyżej 50\%. Samo źródło składa się z trzech generatorów promieniowania laserowego, które połączone razem zasilają tzw. potrójną plamkę. Niezbędne do przesyłania takiej wiązki są także światłowody specjalnej konstrukcji (światłowody te składają się z trzech niezależnych włókien przewodzących promieniowanie, umieszczonych w jednym elastycznym pancerzu).

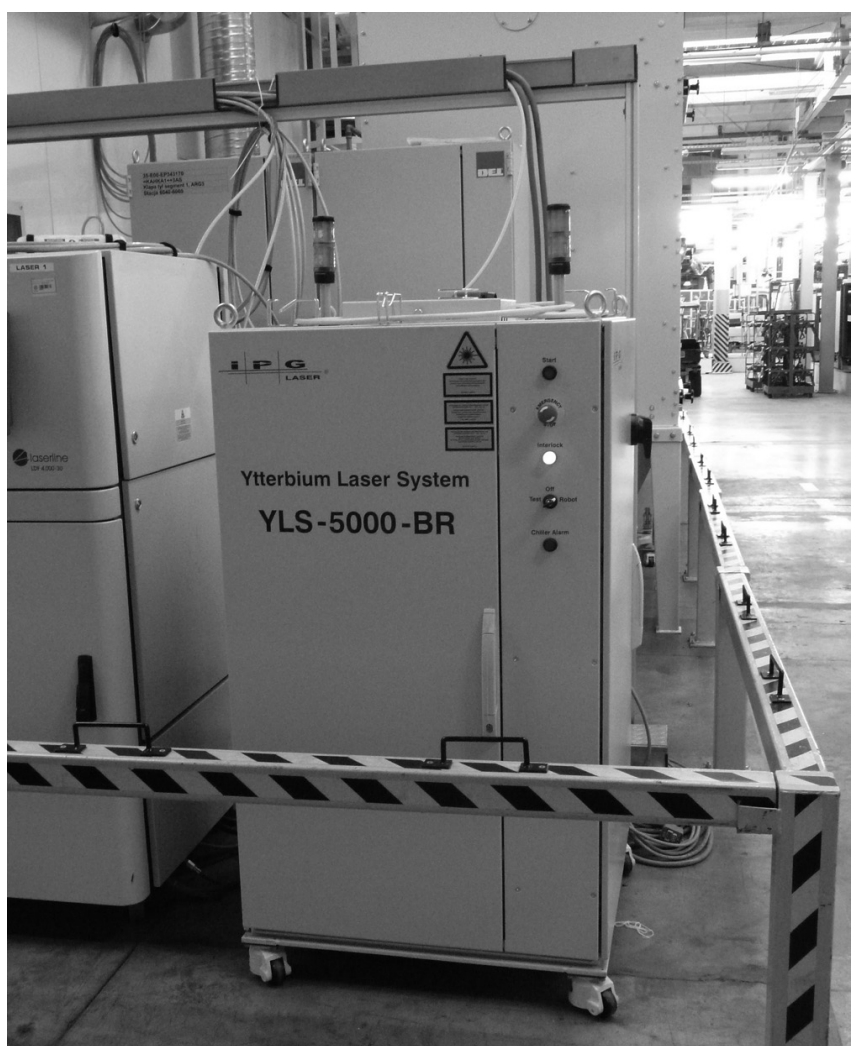

Rys. 2. Źródło laserowe YLS-5000-BR firmy IPG

Fig. 2. Laser source IPG YLS-5000-BR

\section{Technologia}

Technologia zastosowana w tym przypadku określana jest mianem Trifocal ze względu na specyficzny wygląd plamki laserowej, w której koncentruje się energia promieniowania. Jest to potrójna plamka, w której wyróżnić można trzy odrębne ogniska (dwa ogniska pomocnicze oraz jedno główne) [1]. Ogniska pomocnicze usuwają zanieczyszczenia z obszaru brzegów lutowiny (ablacja wierzchniej warstwy materiału) oraz wyznaczają granicę płynięcia lutu, co sprawia, że brzegi lutowiny są równe i pozbawione mikroodprysków i porowatości. Ognisko główne skupia się na materiale i drucie do lutowania powodując jego stopienie oraz płynięcie w granicach wyznaczonych przez ogniska pomocnicze (rys. 3). Taki podział funkcji sprawia, że lutowina ma równe brzegi oraz gładką powierzchnię lica. Moc każdego z ognisk można niezależnie regulować. Moc ognisk pomocniczych wynosi do 0,5 kW, natomiast ognisko główne może mieć maksymalną moc $4 \mathrm{~kW}$. Moc taka w zupełności wystarcza do przeprowadzenia procesu lutowania twardego.

Jest to technologia dość szybka (np. prędkość lutowania zastosowana w fabryce VW w Poznaniu wynosi $50 \mathrm{~mm} / \mathrm{s}$ ), której efektem jest bardzo dobrej jakości złącze lutowane. Materiałami łączonymi są stalowe, ocynkowane elektrolitycznie blachy karoseryjne (grubość warstwy cynku wynosi $5 \mu \mathrm{m}$ ), materiałem dodatkowym jest pełny drut CuSi3 o średnicy $1 \mathrm{~mm}$, temperatura procesu wynosi ok. $1000^{\circ} \mathrm{C}$,

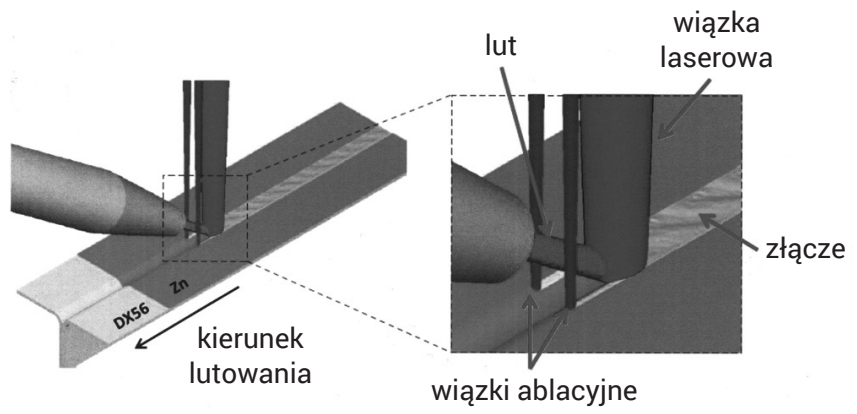

Rys. 3. Schemat lutowania metodą Trifocal [2]

Fig. 3. Brazing with the Trifocal method [2]

moc lasera głównego wykorzystywana w procesie to 2,5 kW, natomiast lasery pomocnicze generują moc po $140 \mathrm{~W}$ każdy. Cały proces jest sterowany przy pomocy komputera z odpowiednim oprogramowaniem, umożliwiającym kontrolę wszystkich parametrów procesu w czasie rzeczywistym oraz ich ewentualną korektę.

\section{Pozycjonowanie części i przygotowanie do lutowania}

Oprzyrządowanie wykorzystywane w tej technologii jest dość skomplikowane ze względu na dużą ilość zacisków pozycjonujących łączone elementy. Jest to niezbędne, aby zapewnić stabilną wielkość szczeliny lutowniczej na całej długości złącza lutowanego. Dodatkowo w tym przypadku w dolnej części szczeliny łączone blachy muszą się stykać ze sobą, aby utrzymać ciekły lut $w$ miejscu tworzenia się połączenia. Używane w zakładzie przyrządy do pozycjonowania łączonych części przedstawia rysunek 4 .

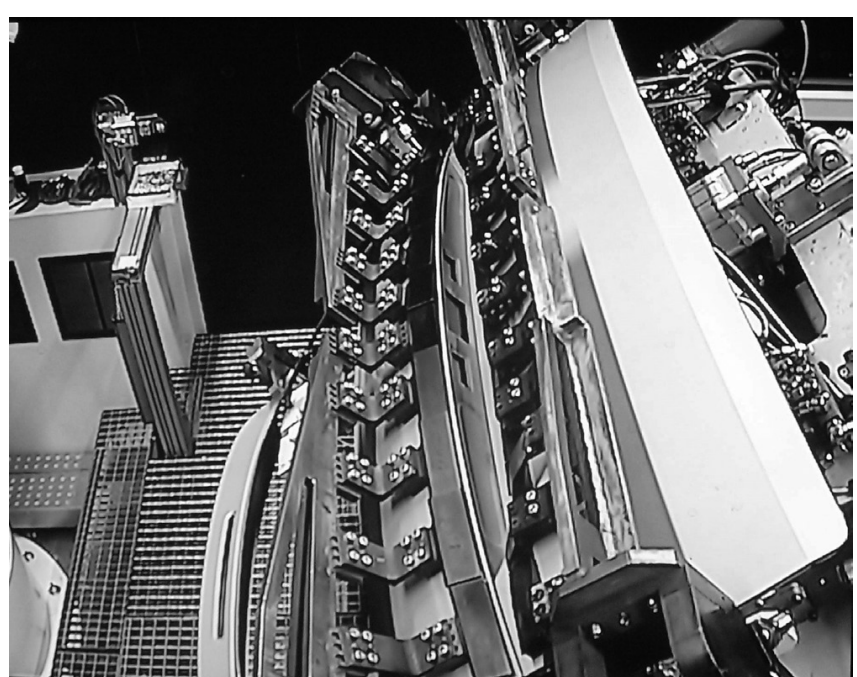

Rys. 4. System zacisków do pozycjonowania łączonych elementów Fig. 4. Fixture system for positioning of joined componts

Przed lutowaniem brzegi łączonych blach są czyszczone mechanicznie z resztek oleju z tłoczni oraz innych zanieczyszczeń, które znalazły się w tym miejscu w trakcie procesu technologicznego, a które mogłyby negatywnie wpływać na jakość złącza. W tym celu jest stosowane urządzenie firmy Vulkan (rys. 5), które przy pomocy specjalnej taśmy czyści obszary łączonych elementów, które zostaną połączone lutem. Mimo starannego przygotowania blach przez dostawcę takie czyszczenie jest niezbędne, czego dowodzi stan szybko zużywającej się taśmy. 


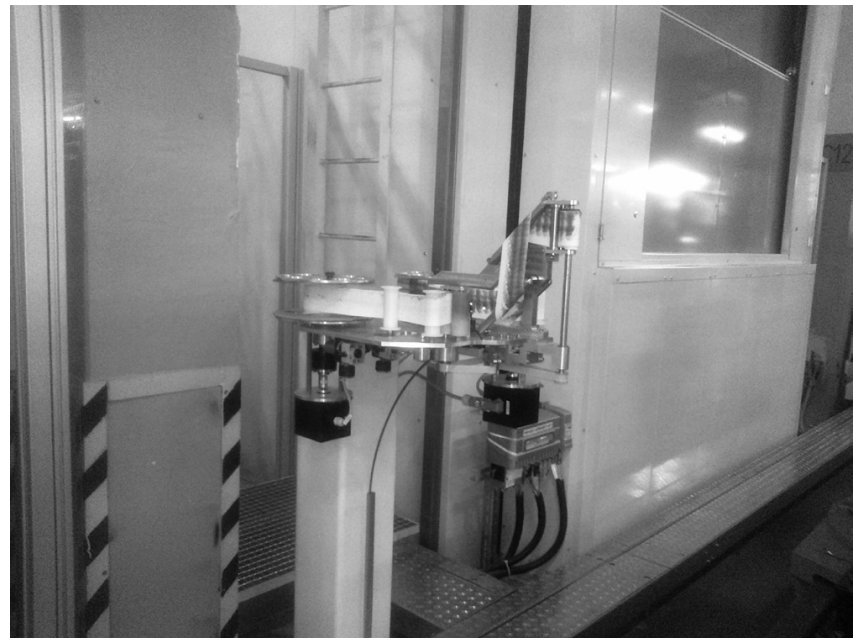

Rys. 5. System zacisków do pozycjonowania łączonych elementów Fig. 5. Fixture system for positioning of joined componts

\section{Kontrola złącza}

Po zakończeniu procesu lutowania złącze jest dodatkowo czyszczone przy pomocy wirującej szczotki z tworzywa sztucznego (rys. 6), aby usunąć zadymienia i nalot powstałe $\mathrm{w}$ trakcie procesu przed kontrolą złącza przy pomocy promieni lasera skanującego (rys. 7), służącego do wykrywania ewentualnych niezgodności powierzchniowych (pory, niedolania, wtrącenia, itp.). Jeżeli w trakcie tej kontroli zostają wykryte niezgodności złącza, to taki produkt zostaje skierowany na stanowisko poprawek, gdzie jest oceniany dodatkowo przez pracownika działu zapewnienia jakości, który podejmuje decyzję o ewentualnej naprawie wadliwego odcinka spoiny lub złomowaniu całego detalu.

Naprawa polega na zaspawaniu wadliwego miejsca metodą GTA oraz jego wyszlifowaniu i ponownej ocenie wizualnej przez pracownika działu zapewnienia jakości.

\section{Badania niszczące}

Dodatkowo w trakcie produkcji seryjnej są pobierane raz $\mathrm{w}$ miesiącu do badań niszczących pojedyncze klapy, aby sprawdzić wewnętrzną budowę połączenia oraz porównać wartości wytrzymałościowe złącza z minimalnymi wymaganiami ustalonymi przez konstruktora. Cała szerokość klapy zostaje podzielona na 14 stref, a każda ze stref jest sprawdzana w ten sam sposób. Sprawdza się geometrię złącza na podstawie zdjęć zgładów metalograficznych oraz wytrzymałość próbek na rozciąganie, następnie z takich badań sporządzane są protokoły kontroli (przykładowy protokół kontroli pokazano na rys. 8), a dane przekazuje się do działu produkcji. W przypadku, gdy połączenie nie spełnia wymagań, następuje optymalizacja parametrów procesu i ponowne sprawdzenie. Takie podejście gwarantuje, że wszystkie klapy mają odpowiednią jakość, a proces przebiega stabilnie.

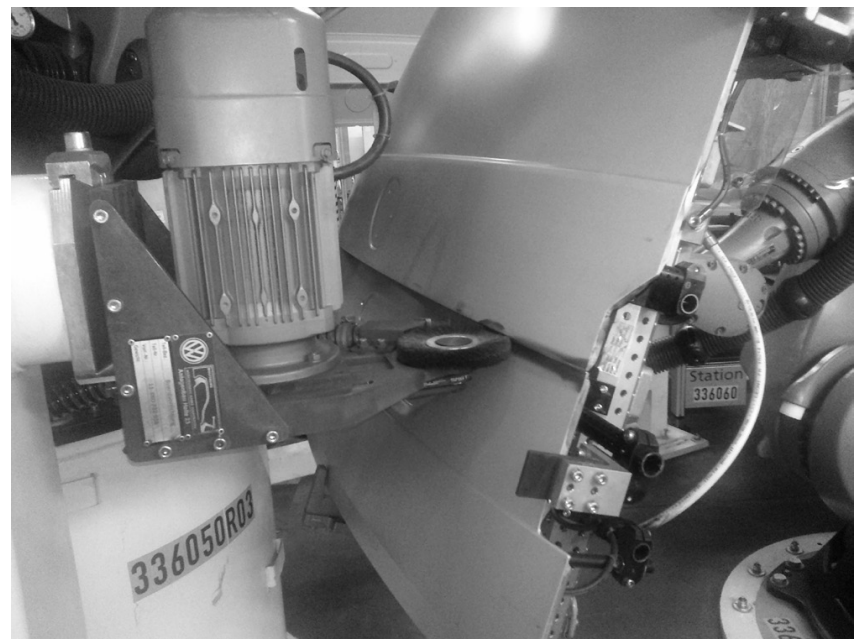

Rys. 6. Czyszczenie złącza przed użyciem lasera skanującego Fig. 6. Cleaning the joint before using the scanning laser

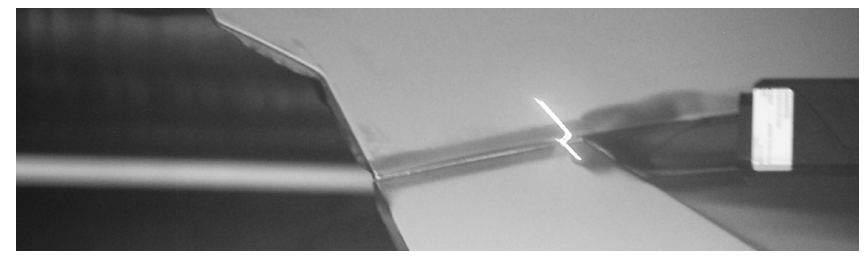

Rys. 7. Kontrola złącza przy pomocy lasera skanującego Fig. 7. Joint test with the use of scanning laser

\begin{tabular}{|l|c|c|}
\hline $\begin{array}{c}\text { Samochody } \\
\text { Użytkowe }\end{array}$ & $\begin{array}{c}\text { Prüfprotokoll } \\
\text { Protokół z kontroli }\end{array}$ & Datum:13.01.2016 r. \\
\hline Früfzentrum Karosseriebau & $\begin{array}{c}\text { Metallographischesprüfung } \\
\text { Badanie Metalograficzne } \\
\text { Laser1øtung / lutowanie laserowe }\end{array}$ & Prüfung nach: PV 1602 \\
\hline
\end{tabular}
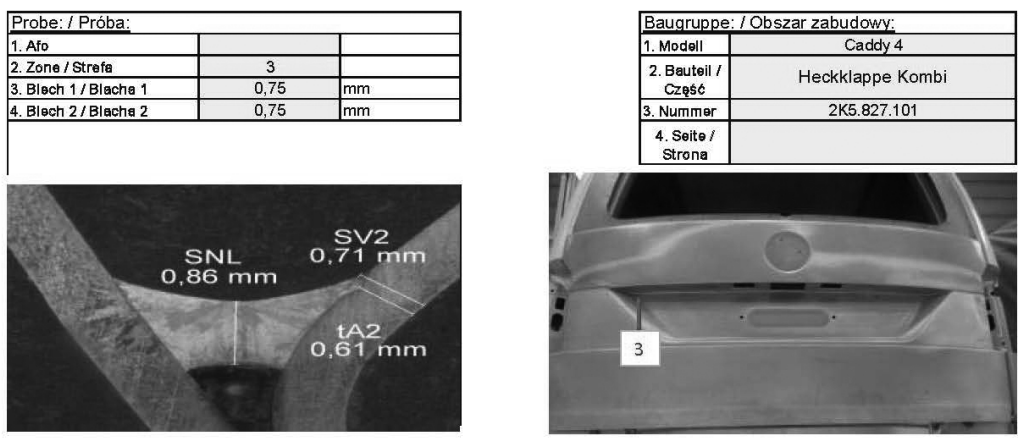

\begin{tabular}{|c|c|c|c|}
\hline \multicolumn{4}{|l|}{ Messung:/ Pomiar: } \\
\hline & soll / powinno & ist / jest & \\
\hline \multirow{2}{*}{ 1. Grubose lutu SNL } & i. $0 \geq 0,60$ & 0,86 & $\mathrm{~mm}$ \\
\hline & b.i.o $\geq 0,53$ & & $\mathrm{~mm}$ \\
\hline \multirow{2}{*}{ 2. Najmniejszza szerokosć poiązzania SK } & $i .0 \geq 0,60$ & & $\mathrm{~mm}$ \\
\hline & b.i.o $\geq 0,53$ & & $\mathrm{~mm}$ \\
\hline 3. Pozostale grubosc blechy tat & $\geq 0,38$ & & $\mathrm{~mm}$ \\
\hline 4. Najmniejsza szerokosć poł qczania SV2 & $\geq 0,60$ & 0,71 & $\mathrm{~mm}$ \\
\hline 5. Poz ostala grubosé blachy thz & 20,38 & 0,61 & $\mathrm{~mm}$ \\
\hline 6. Poryi wtaceniag & i. $0 . \leq 10 \%$ & & $\%$ \\
\hline \multirow{2}{*}{\begin{tabular}{|l|} 
7. Rysyi \\
8. Sita F \\
\end{tabular}} & & & \\
\hline & $\geq 6,378$ & 9,199 & $\mathrm{kN}$ \\
\hline
\end{tabular}

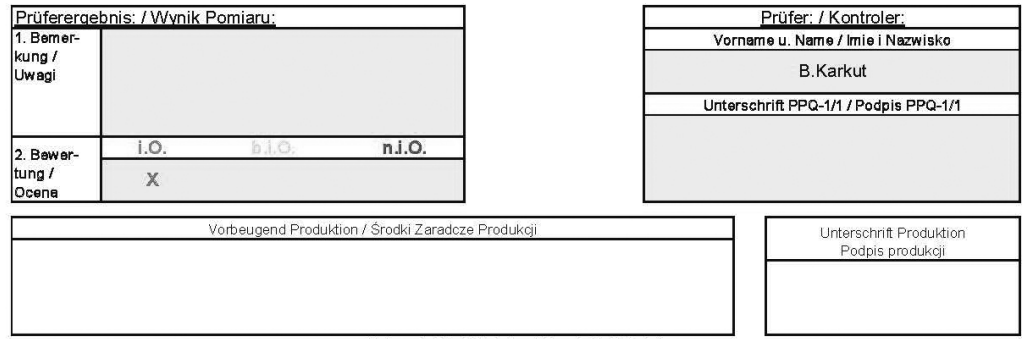

Rys. 8. Protokół z badań niszczących złącza lutowanego

Fig. 8. Report of destructive testing of the brazed joint 


\section{Podsumowanie}

Przedstawiony powyżej proces, czyli technologia lutowania laserowego Trifocal jest bardzo korzystna dla producentów samochodów z następujących względów:

- proces przebiega ze znikomą ilością uwalnianych aerozoli i innych zanieczyszczeń, co oznacza minimalny wpływ zanieczyszczeń na pracowników obsługujących to stanowisko oraz na środowisko naturalne;

- minimalna ilość wprowadzanego do złącza ciepła zmniejsza prawdopodobieństwo wystąpienia odkształceń termicznych łączonych elementów;

- duża szybkość procesu oznacza wysoką wydajność;

- powtarzalność i stabilność procesu wpływa na uzyskanie bardzo wysokiej jakości detali;

- możliwość wykonywania połączeń o skomplikowanej geometrii ułatwia dostosowanie tej technologii do niemal dowolnego kształtu detalu;

- duża sprawność najnowszych źródeł laserowych pozwala na znaczną oszczędność energii, w porównaniu ze starszymi źródłami laserowymi.

Oprócz zalet technologia Trifocal ma wady i ograniczenia:

- mimo systematycznie malejącego kosztu urządzeń, nakłady, związane z ich zakupem (źródło laserowe, głowice laserowe, roboty, kabina) pozostają na dość wysokim poziomie, co ogranicza zasadność zastosowania ich w przypadku produkcji małoseryjnej lub jednostkowej;

- skomplikowana technika pozycjonowania części do lutowania wpływa na koszty ewentualnych napraw i czynności serwisowych w tego typu stanowiskach;

- istnieje ciągle niebezpieczeństwo dla pracowników związane z użyciem promieniowania laserowego, zwłaszcza, gdy w trakcie lutowania w kabinie znalazłby się pracownik.

Bez względu na te ograniczenia Trifocal jest technologią, która jeszcze przez długi czas będzie powszechnie używana w przemyśle motoryzacyjnym, gdyż zalety procesu znacznie przewyższają ograniczenia wynikające zarówno z kosztów jak i zagrożeń związanych z jej zastosowaniem.

\section{Literatura}

[1] http://www.ipgphotonics.com/108/FileAttachment/YLS-5000BR+Brochure.pdf

[2] Strite T., Gusenko A., Grupp M., Hoult T.: Fiber Lasers: Multiple laser beam materials processing, Laser Focus World, vol. 52, issue 02, p. 19-25, 02/2016.

[3] Majeran E.: Lutowanie laserowe w przemyśle motoryzacyjnym na przykładzie połączenia dachu ze ścianami w samochodzie Volkswagen Caddy, Przegląd Spawalnictwa, 09/2007, s. 37-40. 